\title{
A Retrospective Study of Early Discharge and Outcomes of Pre-Term Infants from a Tertiary Care Centre in Rohtas, Bihar
}

\author{
Rambilas Ranjan ${ }^{1}$ \\ ${ }^{1}$ Assistant Professor, Department of Paediatrics, NMCH, Jamuhar, Sasaram.
}

\section{Abstract}

Background: In developing countries parents want early discharge of infants. Preterm infants are at risk of several morbidities if stayed long in hospital. There are different policies for discharge and most rely on achieving a weight of 2000 grams. Recent studies have emphasized the role of physiological parameters to discharge preterm infants. The objective of this study was to find out the outcomes of early discharge of preterm infants from a tertiary care centre in Rohtas, Bihar. Subjects and Methods: This study was a retrospective study. The data was collected from all ex pre-term infants (gestation<34 weeks at birth) admitted in this NICU between 1st January, 2017 to 31st December, 2018 . They were stratified in two groups based on gestation at birth: Group I $(n=70: 26-29$ weeks, Group II $(n=234)$ : $30-34$ weeks. The outcome measure was re-admission and/or mortality within 4 weeks after discharge of all the eligible infants. The reasons for re- admission or mortality were also recorded. Results: The mean \pm (SD) duration of stay was $42.5 \pm 18$ vs $15 \pm 12$ days in group I vs II infants. Two and six infants were readmitted within four weeks after discharge in group I and group II respectively. Conclusion: Early easy home discharge for preterm infants born $<34$ weeks can be done and it is safe and feasible. Large prospective clinical trials are required to confirm these advantages of early home discharge of preterm infants.

Keywords: Home, preterm, readmission, NICU.

Corresponding Author: Dr. Rambilas Ranjan, Assistant Professor, Department of Paediatrics, NMCH, Jamuhar, Sasaram

Received: May 2019

Accepted: June 2019

\section{Introduction}

Clinicians try their best to discharge preterm infants as soon as possible as it ensures parents that their child is not in serious condition. Although decision for the optimal timing of discharge is a tough call. Review of literature suggests that the duration of stay in hospital and post-menstrual age at discharge is inversely proportional to birth weight of neonate and gestation period of pregnancy. There are many morbidities associated with longer hospital stay such as sepsis, chronic lung disease, necrotizing enterocolitis, retinopathy of prematurity (ROP), etc..$^{[1,2]}$

The transition from a protected environment for neonates like Neonatal Intensive Care Unit (NICU) to a new home atmosphere should be smooth and uneventful. But, with decreasing gestational birth age there is high rate of readmission to NICU. ${ }^{[3]}$ There are many factors which are considered before discharging pre-term infants from NICU and this has an impact on home discharge policies of the concerned hospital which varies on individual basis. Some of these factors are as follows: access to health care facilities after discharge, geographic location and other sociodemographic factors. An important criteria to discharge preterm infants in past was achievement of a weight of 2000 grams. However, recent studies have indicated that optimum physiological criteria are a good marker to discharge a preterm as compared to discharge weight. These physiological criteria are as follows: ability to feed to support growth, maintaining temperature, mature respiratory control etc. ${ }^{[4-6]}$ Also, few interventions like oromotor stimulation, Kangaroo Mother Care (KMC), massage, gavage feeding and non-nutritional sucking may help in earlier discharge. ${ }^{[7-9]}$

There is a paucity of literature depicting various factors for early discharge of preterm Infants from NICU in this region of Bihar. The NICU of NMCH, Jamuhar, Sasaram is a busy NICU in a tertiary care teaching hospital in Rohtas, Bihar. This study was done to find out the outcomes of early discharge of pre-term infants from a tertiary care centre in Rohtas, Bihar.

\section{Subjects and Methods}

This study was a retrospective study. The data was collected on all ex pre-term infants (gestation<34 weeks at birth) admitted in this NICU between 1st January, 2017 to 31 st December, 2018. There were 1030 patients admitted in NICU in these two years. Out of these, 463 were pre-term. Among them, 83 died, 42 referred and 34 were LAMA. So, 304 pre-term infants were enrolled for this study. They were 
stratified in two groups based on gestation at birth: Group I $(n=70: 26-29$ weeks, Group II $(n=234)$ : 30-34 weeks. Approval from the institutional ethics committee was obtained before starting the study.

All infants with gestation $<34$ weeks at birth were discharged home during the study period when they fulfilled the following criteria: (a) Stable hemodynamic and respiratory status; (b) Maintaining axillary temperature; (c) On all breasts-feeds or spoon feeds; (d) Weight gain of 20$30 \mathrm{~g} /$ day for three days; (e) Mother confident to look after her baby at home. Oral feeds were started when the infant was cardio-respiratory stable. Readiness to feed was determined by infant's feeding cues i.e., mouthing, rooting and bringing hand to mouth. Apart from supporting breast feeding, we encouraged Kangaroo Mother care (KMC) and spoon feeding for all infants in the NICU as soon as feasible. Estimation of gestation (at birth) was based on the first antenatal ultrasound and the modified Ballard's Score. ${ }^{[10]}$ Weights were measured to the nearest gram using an electronic digital scale. For each group, data on neonatal demographic characteristics and morbidities till discharge home were recorded for all eligible infants. The data were expressed as number (\%), or mean \pm standard deviation (SD), and median (Interquartile range: IQR). Statistical analysis was performed using SPSS software (Version 16.0). The outcome measure was re-admission and/or mortality within 4 weeks after discharge of all the eligible infants. The reasons for re- admission or mortality were also recorded.

\section{Results}

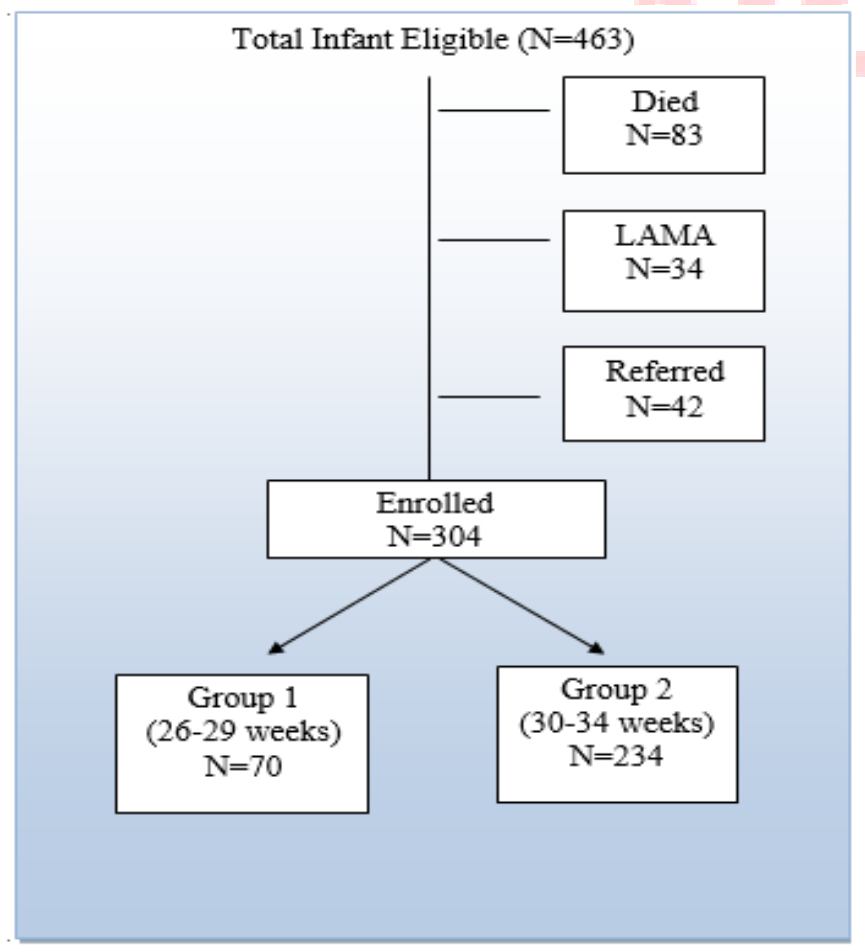

Figure 1: Participants flow diagram
The present study collects a data from 463 ex pre-term infants admitted from NICU. Among them, 83 died, 42 referred and 34 were LAMA. So, 304 pre-term infants were enrolled for this study. They were stratified in two groups based on gestation at birth: Group I $(n=70$ : 26-29 weeks, Group II (n=234): 30-34 weeks. [Figure 1]

[Table 1] shows neonatal demographic characteristics. The median gestational age at birth was 28 years and 32 years in group I and group 2 respectively. The median birth weight was 1008 and 1300 grams in group I and group II respectively. The mean duration of nursery stay was 42.5 days in group I compared with 15 days in group II infants. The median gestational age and weight at discharge was 33 weeks and 1376 grams in group II infants. Various morbidities in both the groups are shown in [Table 2].

\begin{tabular}{|l|l|l|}
\hline Table 1: Neonatal demographic characteristics \\
\hline Variables & $\begin{array}{l}\text { Group 1 (n=70) } \\
\text { Median(IQR) }\end{array}$ & $\begin{array}{l}\text { Group 2 (234) } \\
\text { Median(IQR) }\end{array}$ \\
\hline $\begin{array}{l}\text { Gestational age (GA) at } \\
\text { birth }\end{array}$ & $28(27.35,28.60)$ & $32(31,35)$ \\
\hline Birth weight (grams) & $\begin{array}{l}1008(873.5, \\
1114.75)\end{array}$ & $1298(1172,1413)$ \\
\hline GA at discharge (grams) & $33(32,35)$ & $35(34,37)$ \\
\hline $\begin{array}{l}\text { Weight at discharge } \\
\text { (grams) }\end{array}$ & $1334(1210,1447)$ & $1376(1256,1472)$ \\
\hline Duration of stay (days) & $42.5(30.25,52.50)$ & $15(10,25)$ \\
\hline Re-admission rates (\%) & $2(2.86 \%)$ & $6(2.56 \%)$ \\
\hline
\end{tabular}

Table 2: Neonatal morbidities

\begin{tabular}{|l|l|l|}
\hline Variables & Group 1 (n=70) & Group 2 (n=234) \\
\hline $\begin{array}{l}\text { Blood culture positive } \\
\text { sepsis }\end{array}$ & $9(12.86 \%)$ & $10(4.27 \%)$ \\
\hline NEC stage $\geq 2$ & $3(4.28 \%)$ & $7(2.99 \%)$ \\
\hline IVH & $8(11.43 \%)$ & $8(3.42 \%)$ \\
\hline ROP & $13(18.57 \%)$ & $(0.85 \%)$ \\
\hline BPD & $23(32.86 \%)$ & $9(3.84 \%)$ \\
\hline $\begin{array}{l}\text { Abbreviations: NEC-Necrotising Enterocolitis; IVH-Intraventricular } \\
\text { Hemorrhage; ROP-Retinopathy of Prematurity; BPD-Bronchopulmonary } \\
\text { Dysplasia }\end{array}$ \\
\hline
\end{tabular}

\section{Discussion}

Preterm birth is the second largest direct cause of child deaths in children younger than 5 years. Yet, data regarding preterm birth (<37 completed weeks of gestation) are not routinely collected by UN agencies, and no systematic country estimates nor time trend analyses have been done. The burden of preterm birth is substantial and is increasing in those regions with reliable data. Improved recording of all pregnancy outcomes and standard application of preterm definitions is important. ${ }^{[1]}$ The burden of small-forgestational-age births is very high in countries of low and middle income and is concentrated in south Asia. Implementation of effective interventions for babies born too small or too soon is an urgent priority to increase survival and reduce disability, stunting, and noncommunicable diseases. ${ }^{[12]}$ 
The birth weight and gestation and corrected gestation and weight at discharge for group I (26-29 weeks at birth), and group II (30-34 weeks) infants and their duration of NICU stay are shorter than that reported from previous studies in similar set ups. Mokhachane et al. assessed the outcomes of preterm Very Low Birth Weight (VLBW) infants discharged early at weight $\geq 1650 \mathrm{~g}(\mathrm{n}=62)$ compared with $\geq 1800 \mathrm{~g}$ as per routine practice $(n=62)$ in a Randomized Controlled Trial (RCT). Of the total 120 infants who were followed, the rate of gain in weight and head circumference were similar in both groups. The number of re-admissions and mortality after discharge were also similar among the two groups. It was concluded that, if home circumstances are adequate, it is as safe to discharge well, singleton VLBW infants from hospital at a weight of $\geq 1650 \mathrm{~g}$ or $\geq 1800 \mathrm{~g} .{ }^{[13]}$

Cruz et al., conducted a RCT, discharging VLBW infants at

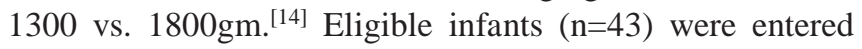
into the study at 1300 to $1350 \mathrm{gm}$ when they met behavioral criteria for discharge and the family home was approved. Follow-up showed no differences in weight gain or incidence of infection in the home vs. hospital group infants. A significant saving in hospital stay and costs was realized for the home group. Family co-operation was more in the home group. ${ }^{[14]}$

Studies reporting on discharge policies for preterm infants from developed nations are limited. Altman et al., assessed the Post-menstrual Age at Discharge (PMAD) for moderately preterm infants $(\mathrm{n}=2388$, gestation at birth: 30 34 weeks) and its relation to peri-natal risk factors and the organization of care in Swedish perinatal network units. The mean PMAD was 36.9 (1.7) weeks. High ( $\geq 35$ years) maternal age, multiple birth, small for gestational age, respiratory distress syndrome, infection, hypoglycaemia and hyperbilirubinemia were significantly associated with higher PMAD, but could explain only $13 \%$ of its variation. Mean PMAD differed by up to 2 weeks between hospitals. They concluded that, perinatal risk factors had small overall impact on length of hospital stay in moderately preterm infants, whereas, organization of care was probably an important factor. ${ }^{[15]}$

A study from Singapore (2008) audited the discharge patterns of 36 preterm infants. The underlying causes leading to and the root causes of discharge delays were identified as requiring goal weight of $2 \mathrm{~kg}$, even when medically fit, delayed delivery of discharge plan to parents, delayed discharge planning and no ownership in discharge planning. The length of hospital stay was reduced $59.8 \%$, primarily by improved discharge planning, revising discharging weight guidelines and mental and psychological preparation of parents for infant care at home. ${ }^{[16]}$

A recent report from the Canada indicates that infants born at $<34$ weeks' gestation are usually discharged between 37 and 40 weeks. In their system, $50 \%$ of preterm infants $<37$ weeks' gestation at birth are discharged home directly from tertiary NICUs, and the remainder are transferred to community hospitals before discharge. Merritt et al. pointed out that early discharge is clearly achievable for a large number of infants despite the variations in neonatal care practices that, influence NICU stay. ${ }^{[17]}$ Soni A et al did a study on preterm infants and indicated that early discharge of preterm neonates from the NICU at a much lower weight and post-natal age is feasible in a resource poor set-up. ${ }^{[18]}$

\section{Conclusion}

Preterm infants born $<34$ weeks can be discharged early and it is safe and feasible. Large prospective clinical trials are required to confirm these advantages of early home discharge of preterm infants. Various interventions like kangaroo care, spoon feeding and parental participation will facilitate early discharge.

\section{References}

1. Rawlings JS, Scott JS. Post-conceptional age of surviving preterm lowbirth-weight infants at hospital discharge. Arch Pediatr Adolesc Med. 1996;150:260- 62 .

2. Hintz SR, Bann CM, Ambalavanan N, Cotten CM, Das A, Higgins RD. Predicting time to hospital discharge for extremely preterm infants. Pediatrics. 2010;125:e146-54.

3. Elder DE, Hagan R, Evans SF, Benninger HR, French NP. Hospital admissions in the first year of life in very preterm infants. J Paediatr Child Health. 1999;35:145- 50.

4. Shah PS, Lee SK, Yoon W, Chan P, Param V. Members of the Annual Report Review Committee. The Canadian Neonatal Network annual report. 2011. Available at http://www.canadianneonatalnetwork.org/Portal/LinkClick.aspx?filetic ket $=r C V w k K 1 A 4 p c \% 3 D \& t a b i d=39$ [Accessed on June 1, 2019]

5. American Academy of Pediatrics Committee on Fetus and Newborn. Policy statement: Hospital discharge of the high-risk neonate. Pediatrics 2008;122:1119-26.

6. Jefferies AL, Canadian paediatric society, Fetus and newborn committee. [9] Going home: Facilitating discharge of the preterm infant. Paediatr Child Health. 2014;19(1):31-36.

7. Conde-Agudelo A, Díaz-Rossello JL. Kangaroo mother care to reduce morbidity and mortality in low birthweight infants. Cochrane Database Syst Rev. 2014;4:CD002771.

8. Wang L, He JL, Zhang XH. The efficacy of massage on preterm infants: a meta-analysis. Am J Perinatol. 2013;30(9):731-38.

9. Pinelli J, Symington A. Non-nutritive sucking for physiologic stability and nutrition in preterm infants. Cochrane Database Syst Rev. 2005;(4):CD001071.

10. Ballard JL, Khoury JC, Wedig K, Wang L, Eilers-Walsman BL, Lipp R. New Ballard Score, expanded to include extremely pre-mature infants. J Pediatr. 1991;119:417-23.

11. Blencowe H, Cousens S, Oestergaard MZ, Chou D, Moller A- B, Narwal R, et al. National, regional, and worldwide estimates of preterm birth rates in the year 2010 with time trends since 1990 for selected countries: a systematic analysis and implications. Lancet. 2012;379:2162-72.

12. Lee AC, Katz J, Blencowe H, Cousens S, Kozuki N, Vogel JP, et al National and regional estimates of term and preterm babies born small for gestational age in 138 low-income and middle-income countries in 2010. Lancet Glob Heal. 2013;1:e26-36.

13. Mokhachane M, Saloojee H, Cooper PA. Earlier discharge of very low birthweight infants from an under-resourced African hospital: A randomised trial. Ann Trop Paediatr. 2006;26(1):43-51.

14. Cruz H, Guzman N, Rosales M, Bastidas J, Garcia J, Hurtado I, et al. 


\section{Ranjan; Early Discharge and Outcames of Pre-Jerm Infants}

Early hospital discharge of preterm very low birth weight infants. J Perinatol. 1997;17(1):29- 32.

15. Altman M, Vanpée M, Cnattingius S, Norman M. Moderately preterm infants and determinants of length of hospital stay. Arch Dis Child Fetal Neonatal Ed. 2009;94(6):F414-18.

16. Lian YC, Ying SH, Peng CC, Yann TY. Early discharge Study for premature infants: Singapore General Hospital. Perm J. 2008;12(4):15-18.
17. Merritt TA, Pillers D, Prows SL. Early NICU discharge of very low birth weight infants: A critical review and analysis. Semin Neonatol. 2003;8(2):95-115.

18. Soni A, Kadam S, Pandit A, Patole S. Early Discharge of Preterm Infants- An Indian Perspective. J Clin Diagn Res. 2016 Dec;10(12):SC21-SC23.

Copyright: (C) the author(s), 2019. It is an open-access article distributed under the terms of the Creative Commons Attribution License (CC BY 4.0), which permits authors to retain ownership of the copyright for their content, and allow anyone to download, reuse, reprint, modify, distribute and/or copy the content as long as the original authors and source are cited.

How to cite this article: Ranjan R. A Retrospective Study of Early Discharge and Outcomes of Pre-Term Infants from a Tertiary Care Centre in Rohtas, Bihar. Asian J. Clin. Pediatr. Neonatol.2019;7(2):27-30.

DOI: dx.doi.org/10.21276/ajcpn.2019.7.2.7 